Sustainability in Practice:

Exploring the Objective and Subjective Aspects of Personhood

\author{
Hélène Cherrier, $\mathrm{PhD}^{*}$ \\ Senior Lecturer \\ Griffith Business School \\ Building N63, Room 2.09 \\ Nathan campus, Griffith University, \\ 170 Kessels Road, Nathan QLD 4111, Australia
}

Phone: +61 737357304

Fax: +61 737357126

Email: $\underline{\text { h.cherrier@griffith.edu.au }}$ 


\section{Sustainability in Practice:}

\section{Exploring the Objective and Subjective Aspects of Personhood}

Central to academic and policy debates, the notion of sustainable consumption is often referred to as: "the use of goods and related products which respond to basic needs and bring a better quality of life, while minimising the use of natural resources and toxic materials as well as the emissions of waste and pollutants over the life cycle, so as not to jeopardise the needs of future generations" (Thogersen, 2005; Heiskanen and Pantzar, 1997). This definition indicates that environmental degradation is not the sole problem of governments, businesses or non-profit organizations but results from the choices individuals make in their everyday lives. For consumers to integrate sustainability into their lives, they are called upon to consider the environmental impact of their personal consumption practices and modify their lifestyle, either by making green choices (i.e.: purchase green) and/or lowering their level of consumption (i.e.: use less).

In sustainable consumption literature, the emphasis on the consumer has led to three main approaches. First, some theorists adopt a voluntarist approach whereby individuals make choices actively, voluntarily and autonomously. Under this lens, sustainable consumption is a matter of information and individual choice. Consumers are informed on the environmental impact of the product they use. From this learning, consumers are hoped to change their consumption practices and adopt a sustainable lifestyle that demonstrates environmental responsibility. For example, the UK campaigns "Helping the Earth begins at Home" (Hinchlifffe, 1996) and "Are you doing your bit" (Cohen and Murphy, 2001) inform on the consequences of individual consumption practices on environmental problems and attempt to create a sense of personal responsibility and duty. In support to this voluntarist approach are the studies that discuss how responsible shopping has gained a political 
significance and thereby ascribe the consumer to an ethical / sustainable voter who exercises consumer choices to send market signals (Shaw et al. 2006, Connolly and Prothero 2003, Prothero and Fitchett 2000).

Other theorists prioritize a determinist view arguing that consumption choices are constrained by structural forces. For example, our cultural emphasis on physical mobility, cleanliness, or comfort may be seen as structural constraints to the neo-liberal conception of freedom of choice (Cherrier et al. 2012, Shankar et al. 2006). In this view, sustainable consumption is not a matter of autonomous choices but a practice situated in relation to wider structural forces. In focusing on the constraining forces to consumption choices, this approach places its effort in politicizing environmental reforms and proclaims the need to identify norms of conduct that delineate the way individuals should live and consume. For instance, Seyfang discusses the concept of ecological citizenship (Seyfang, 2006) and Bell offers the notion of green citizenship to delineate consumers' obligations toward the natural environment (Bell, 2004). Both concepts represent the development of social norms, principles for behaviour and control for actions as drivers of environmental or eco-friendly practices. Extrapolating this perspective to transformative marketing, sustainable consumption will be shaped by the structural ideology of the marketplace and policy makers.

A third approach highlights the dynamic interplay between the individual and structural forces. For example, Cherrier and Murray (2007) argue that adopting a sustainable lifestyle emerges from individual characteristics, tastes, and preferences and is shaped by a complex system of social, cultural, and material (re)production. Sustainable consumption practices result from an active process carried out within enabling and constraining forces imposed by the material situation (i.e.: global warming, waste, pollution) and structural power (Collins, 2004; Varul, 2009). As consumption choices represent a constant navigation between the individual and the turbulent and fragmented nature of society, it is often 
experienced as individually challenging and even contradictory (Chatzidakis et al., 2004; Connolly and Prothero, 2008; Cherrier and Murray, 2007). Within this perspective, transformative marketing needs to move away from linear models that position the sovereign consumer at one end and structural constraints at the other and develop models that involve dialectical interplays and highlight both the limitations and potentials of responsibilizing the consumer and/or promoting micro-political lifestyles (Lewis and Potter 2011, Micheletti et al. 2009).

Whilst these advances in sustainable consumption research may have led to increased knowledge about practices and brought about favourable consumer attitudes toward acting sustainably, it had not translated to mainstream consumers' adoption of sustainable practices (Thogersen, 2005; Shove, 2005; Prothero et al., 2011). For example, consumers purchase environmentally hazardous products regardless of their understanding of the link between consumption and environmental degradation (Shove 2005) or act unethically regardless of their adherence to norms of behaviour that guide marketplace behaviour (Strutton et al. 1994, Chatzidakis et al. 2004). In this study, I argue that part of this failing is due to the Western fascination with the individual and the insufficient attention paid to the social context that gives meanings to sustainable consumption. Indeed, in the approaches described above, the social context in which people interact is acknowledged, yet remains secondary to sustainable consumption practices. In the voluntarist approach, sustainable consumption serves as a potential signifier for the environmentally concerned individual who autonomously chooses positively valued practices. In the determinist approach, the practice is a response to preestablished guidelines imposed on the individual. In the dialectical approach, sustainable consumption serves as the locus of individual identity construction, negotiated in interplay between individual choices and the enabling and constraining structural forces. Most notably 
is that most discussions of sustainable consumption remain outside of the specific conceptions and subjective interpretations of the practice.

The aim of this study is to consider how sustainable consumption practices are brought into relationship with other things, people and ideas that inhabit the social space of consumers. This question contributes to a core problem in sustainable consumption research which is to better understand how aspects of sustainable consumption become salient for and incorporated into one's lifestyle and one's identity. For this purpose, I investigate how sustainable consumption is perceived, interpreted, experienced and appropriated by different individuals in their social context. I use the conceptual lens of personhood, as opposed to the individual, as it recognizes that identity, actions, and motivations are shaped by one's membership in a social unit. As La Fontaine (1985, p.124-126) argues: "the individual refers to a biologically distinct, socially discrete, indivisible being, a unity of body and mind; the person, to an ensemble of social roles and relations; the self, to a unique identity." He further argues that in the West, the ideological predominance of individualism has led to a collapse of the person into the individual and both into the self. In the following discussion, a review of the anthropological and sociological approaches to personhood is presented. Following the methodology, the findings provide insights in the relevance of others in shaping meanings of sustainable consumption. The conclusion calls transformative marketing research to consider the concept of personhood when researching, prescribing, defining and evaluating sustainability policies and consumer practices.

\section{Personhood}

Although studies on sustainability and consumer behaviour do not differentiate notions of individual and personhood, sociologists and anthropologists insist on a fundamental distinction between each concept (Jenkins, 1996; La Fontaine, 1985; Mauss, 
1985; Mauss, 1950; Fortes, 1973; Goodenough, 1965)(Bailie 2006, Mauss 1939, Rorty 1989, La Fontaine 1985, Rorty 1976); as La Fontaine (1985, p. 124-126) underlines “orthodox anthropological usage has long distinguished the person from both the individual and the self."

Considering the history of 'personhood', the notion seems to have first appeared in context of the Roman theatre as dramatis personae. The Latin verb for 'speaking through': 'personare' and the noun 'personae' point to the actors speaking through a mask. Behind the mask, "the person thus comes to stand behind his roles, to select them and to be judged by his choices and his capacities to act out his personae in a total structure that is the unfolding of his drama" (Rorty, 1976, p. 309). The Greeks also referred to the actor wearing the mask, named 'propopon,' to develop the idea of the person and personhood. According to this theatrical paradigm, a person's personhood results from "speaking through the mask of another" (Baili 2006, p. 21). As a result of the mask, the actor has become a person, thus the word persona came to refer both to the actor and the role that the actor performed (Rorty, 1976, p. 311). Important to the original sense of the term is that personhood or "the sense of being a 'person' is intimately linked with our interaction with other persons" (Gillett \& Peacocke, 1987, p. 5).

Differentiating the Western notion of the 'individual' rooted in "the gesture of disidentification with which the individual distinguishes himself from others" (Bailie, 2006, p. 20), Bailie points to the significance of intersubjectivity of personhood and emphasizes “for Jesus' own personhood was defined by his Trinitarian consubstantiality with the Father" and "Christian personhood is defined by the Imitatio Christi" (2006, p. 21). Similarly, Jenkins (1996) contrasts the concept of personhood from the autonomous internal self, which evokes reflexivity and independence and the plastic external self dominated by society and cultural forces. Clear to these approaches is that personhood, in contrast to individual, recognizes the 
interdependence of actors and points to the ways 'persons' are understood and constructed in particular social contexts (Gaylin and Jennings 2003, La Fontaine 1985). For Buber (2002, p. 250), a person is at all times involved with the world by either engaging with other individuals, inanimate objects or all reality in general. As "all real living is meeting" (Buber, 2002, p. 250), "the isolated individual is an illusion. If we unravel the network of social contracts, the knots disappear" (Gaylin and Jennings, 2003, p. 212). The importance of the social context when discussing personhood is further highlighted in Jenkins' (1996) definition of personhood as "the individual's reflexive sense of her own particular identity, constituted vis à vis others in terms of similarities and differences, without which she would not know who she was and hence would not be able to act" (Jenkins 1996, p. 52).

According to Fortes (1973), there exist two essential aspects in the concept of personhood. The first, named the objective side, represents "the distinctive qualities, capacities and roles with which society endows a person enable the person to be known to be, and also to show himself to be the person he is supposed to be" (p. 287). The objective side of personhood mirrors Du Gay's (2004, p. 151) notion of the "socially and culturally instituted forms of personhood," which "are not unitary and continuous but technical and limited” (Du Gay 2004). They represent “"specific forms of 'personhood,' which individuals acquire as a result of their immersion in, or subjection to, particular normative and technical regimes of conduct' (Du Gay, 2007, p. 11). Accounts of the objective side of personhood are also offered by Mauss (1939) who discusses 'la personne morale' as the outer persona or mask that one presents to the world. Considered as a 'personne morale', the person is culturally objectified, fitting particular socially and culturally constructed categories. The focus is on the ideological definition of personhood in terms of rules, roles, and representations and the person is understood in terms of category (Mauss 1939). Within sustainable consumption research, the objective aspect of personhood is noticeable in the few 
studies that discuss the socio-cultural construction of sustainable/green practices and identities. For example, Autio et al. (2006) note the influence of educational school material, topical campaign themes and representations from popular culture and the media on the construction of sustainable identity positions such as the anti-hero, the environmental hero and the anarchist (Autio et al., 2009). Similarly, Connolly and Prothero (2003, 2008) argue that marketplace and the commodity discourse helps shape the 'material greens' and Varul (2009) discusses the development of 'ethical selving' enabled by a process of increased individualization and global consumer culture. Studying new consumption communities, Berkin et al (2006) also identify the influence of the collective in shaping meaningful sustainable consumption practices and identities (Berkin et al., 2006). These studies commonly identify categories of sustainable consumer identity and practices that individuals acquire as a result of their immersion in normative guidelines and principles for sustainable consumption. While this socially generated and culturally defined perspective links to the notion of personhood, it mainly focuses on the objective side of personhood and, thus, provides only a partial explanation of participation and of non-participation in sustainable consumption.

Fortes (1973) identifies a second aspect of personhood, named the subjective side, which "is a question of how the individual, as actor, knows himself to be - or not to be - the person he is expected to be in a given situation and status" (p. 287). Recognizing the subjective side of personhood emphasizes that, in order to embrace a certain role in society, human beings need to appropriate to themselves the socially constructed roles that society has defined. As Fortes explains "for it is surely only by appropriating to himself his socially given personhood that he can exercise the qualities, the rights, the duties and the capacities that are distinctive of it" (p. 311). The subjective side of personhood is also offered in Mauss' (1939) notion of ' $m o i$ ' - the awareness of self. This aspect of personhood - 'le moi' - 
represents the inner, elusive experience of the person. The focus is on the subjectively apprehended aspects of social life and the person is understood as a categorizer instead of a simple category (Jackson and Karp 1990). Considering the subjective aspect of personhood, the attention shifts from "the outer persona or mask which a person presents to the world, to those particular contingencies which make each of us 'I' rather than a copy or replica of somebody else" (Rorty 1989, p. 25). In this sense, personhood is understood as interplay between culturally objectified and subjectively apprehended aspects of social life.

Incorporating the notion of personhood requires understanding the structural influences that shapes one's identity and practices. This, according to Gillespie, is instantiated in practices, including day-to-day routines and mundane practices amongst others. As Du Gay, Salaman and Rees (1996, p. 264) emphasizes, "the adoption of certain habits and dispositions allows an individual to become - and to become recognized as - a particular sort of person" (Du Gay et al. 1996). This view implies that personhood is in continuous becoming through processes of role incorporation in daily practices.

This study uses the conceptual lens of personhood to analyse the particular ways in which relations between people, consumption and sustainability are set up and contrasted to the social and cultural vision of sustainable consumption. In particular, the subjective aspect of personhood allows exploring sustainable consumption as an evolutionary process wherein people are made central to a project in line with certain utopian visions, and thereby partially constrained by socially constructed roles, rules and symbolics. To consider part of sustainable consumption as an evolutionary process of incorporating socially constructed roles points to possible misunderstandings, confusion and substantial resistance against social and cultural configurations of the environmental impact of consumption.

\section{The Study}


Arising out of the discussion on personhood and particularly from its emphasis on the interplay between the "culturally objectified and subjectively apprehended aspects of social life" (Jackson and Karp, 1990, p. 15), is the need to consider the varied ways consumers come to an understanding of and experience sustainable consumption. Such approach requires analysing how the varying patterns and habits of sustainable consumption are contextualized into the implicit, everyday and micro-level social and material environment of the consumer. Toward this aim, this study takes an existential-phenomenological approach, which provides the perfect platform for a deep understanding of individuals' mundane everyday experience of sustainable consumption in relation to their environment, their consumption habits, and the meanings that emerge from the process (Thompson et al., 1989).

Phenomenology, as discussed by Husserl (2000), proposes that a phenomenon be described instead of explained or analysed with causal relations (Husserl 2000). Based on Husserl's (2000) emphasis on understanding the 'life-world,' which is neither mental nor physical, but is happening or occurring, Merleau Ponty adds that phenomenology is a philosophy that sees people in a world that already exists before any reflection. Merleau Ponty's phenomenology is existentialist in the sense that it deals with the existence of people living in, engaging in and experiencing the world (Merleau Ponty 1942). This perspective emphasizes the co-constitution of human existence and the world and allows capturing the alternative ways in which sustainable consumption occurs in and as world relationships.

For this study, ten existential-phenomenological interviews focusing on how informants invest themselves in sustainable consumption and give meanings to the practice have provided the textual data for analysis. The recruitment of informants started with an advertisement posted in two local magazines asking for individuals who embrace sustainable consumption to participate in a study. Considering the low response to the advertisement, I also used my personal contacts with members of an organic food-store. This selection process 
offered access to ten informants, which is an adequate number for this form of research (Denzin and Lincoln, 1998; Thompson et al., 1989). Each selected informant was a selfproclaimed sustainable consumer (i.e.: a person who practices sustainable consumption) and was willing to voluntarily participate in an interview aimed at understanding their sustainable consumption experiences, as well as their feelings and perception of the practice.

The interviews followed the design discussed by Thompson et al. (1989) and were directed as an open dialogue to encourage informants to describe their lived experiences of sustainable consumption. During each interview, the intent was to audio record the details, with all their subtle insinuations and suggestions, of each self-proclaimed sustainable consumer's standpoints, appreciations, experiences and perspectives of sustainable consumption. The interviews were conducted in the informant's home and lasted between 50 to 120 minutes. Each recorded interview was transcribed verbatim and provided the textual data for analysis.

The hermeneutic analysis of the 'text' of consumer stories is a methodology of interpretation and involves rigors rather numerical precisions and generalizations are not intended (Thompson et al., 1989). With the intent to understand how sustainable consumption practices are brought into relationship with other things, people and ideas that inhabit the social space of consumers, the interpretation of the text was formed and challenged through an ongoing interactive process between the participants' perspectives and meanings and my own interpretation as a researcher, which is another perspective, that of scientific knowledge. The first analytical step is the intra-text analysis, which considers each of the ten sustainable consumption stories separately. Each portion of the story is interpreted in relation to earlier portions and later portions of the story, focusing on the temporal sequencing of key events and on the narrative framings or symbolic parallels among the meanings of events and actions (Thompson 1997). The second stage represents the interpretation of each interview in the 
context of all other interviews. During this inter-case analysis, I considered the common story lines between sustainable consumption stories and related each overreaching theme to the culturally objectified (the objective aspect of personhood) and the subjectively apprehended aspects of social life (the subjective aspect of personhood). This process of identifying, grouping and regrouping themes continued until I was able to identify holistic meanings on how informants weave personal perceptions of sustainable consumption in concert with others and out of the diverse socially and culturally shaped visions of sustainable consumption. This process lead to one major theme entitled 'the burden and hardship of sustainable consumption', which comprises three sub-themes named 'one-dimensional view of consumption as wasteful,' 'an absence of critical reflection', and 'sense of social exclusion', and a second major theme named 'natural occurrence of sustainable consumption practices', which includes two sub-themes entitled: 'absence of absolute good or absolute norms' and 'integration of the practice within a complex set of relationships' (see figure 1).

\section{Findings}

The analysis shows a consensus among informants on the why of sustainable consumption. In the narratives, the logic for linking sustainable practices to personal lives was explained in reference to prevailing environmental and public policy discourses that emphasize the environmental impact of individual consumption (Connolly and Prothero, 2003; Sachs, 1999; Prothero and Fitchett, 2000). In effect, the consumers in this study expressed extended environmental knowledge on the ecological impact of consumption and described a sense of responsibility in minimizing their carbon footprint. Principally, they referred to the threat of exhaustion of natural resources, the production of toxic emissions and waste and, ultimately, ecological decline as rationales for adopting a sustainable consumption practice. 
Although informants consistently framed their sustainable consumption around environmental preservation, their lived-experiences were distinctly different. In other words, they all acknowledged and approved the same environmental discourse on consumption but internalized it differently. Whilst some described sustainable consumption as a daily burden, others explained the practice naturally occurring as part of their everyday life. The themes below discuss the divergent experiences and exemplify contrasted roles, rules and symbolic of sustainable consumption. The discussion emphasizes the diverse subjective process of internalizing the link between sustainability and consumption.

\section{The Burden and Hardship of Sustainable Consumption}

This first theme shows sustainable consumption experienced as a daily burden. Three particular aspects denote this theme: a one-dimensional view of consumption as wasteful, an absence of critical reflection and a sense of social exclusion.

Informants who experienced the burden of living sustainability categorized consumption in general as a destructive practice constructed around individualistic, careless and egoistic concerns. As Patrick explains, "I believe that, individual consumption of resources or having many possessions is not good for, not good for the environment." In describing consumption in general as "not good" (Camilla) "wasteful" (Marius), "unsustainable" (Jeff), and "environmentally damaging" (Helen), informants posit consumption as a negative practice, which they categorically identify as the cause of the planet's environmental and ecological degradation. In the narratives, this negative vision of consumption is contrasted to the positive image of green / sustainable consumption practices that, again, emerged as a reaction against global warming and environmental degradation. Identified as a practice that is positively valued and contrasted to negatively valued consumption practices, sustainable consumption inevitably displaces the pleasure, delight and enjoyment of consuming and 
causes feelings of "guilt when buying things" (Helen), when consuming non-renewable energy (Patrick), and when "generating waste" (Deidra). Clear to the narratives is that no one can escape consumption or live without consuming. By embracing a one-dimensional vision of consumption as negative and wasteful and yet, at the same time, being faced with the necessity of consuming, informants discussed adopting a sustainable consumption lifestyle in terms of "constant efforts" (Deidra), "hardship" (Patrick), "difficulties" (Helen), "burden of knowing about environmental degradation" (Camilla), and struggles to "constantly think about the environment when consuming" (Jeff). Helen describes sustainable consumption as: "it actually really is a burden. I feel bad every time I feel like maybe I bought a piece of clothing that was made in a sweatshop. I feel psychosocially quite burdened." In the excerpt below, Deidra defines her sustainable consumption lifestyle as a daily struggle and constant hardship.

Everything I do is like so hard. It's hard. When you go shopping you just can't buy something. You have to look at where it was made, what it contained and how it's packaged and then when you get home and you've got your rubbish, you just can't put in the rubbish bin. I mean my rubbish bin goes out once every four months, if you're lucky and I have like six different recycle bins. Well actually it's not that bad now cause now I can put all my plastic and all my cans and my glass in one container. We don't have collections here. They don't collect recycle. So I end up with a car load of bottles in one bag and cardboard in another and white paper in another, you know, waiting until I get to the recycling bin can and I mean you know, it's not like I had to do it. It's just a part of who I am, cause sometimes you just go, Oh, my God, it's so hard. (Deidra) 
Deidra is a fifty-eight year old single woman from New Zealand. She grew up in an 'environmentally conscious environment' and defines her parents as 'caring for our natural habitat.' Concerned with environmental degradation from a very young age, Deidra completed a bachelor in science and became an environmental activist. Deidra's central sustainable consumption project is to oppose consumption and waste. She explains: "I hate packaging and I make myself responsible for any rubbish I generate. So consequently I am continuing trying to reduce the amount of rubbish that I do generate, because as soon as I generate it, I become responsible for it." A close read of Deidra's narrative indicates that the hardship and struggles to adopt and maintain a sustainable consumption lifestyle is linked to an uncritical acceptance of public policy discourses and socio-cultural shaping of individual consumption as the defining condemnation (Prothero and Fitchett 2000, Connolly and Prothero 2003). This absence of critical reflection leaves Deidra caught up in a sphere of normativity and regime of truth constructed on a strong negative vision of consumption in general, isolated from any possible negotiation, dialogue and encounter with others. According to Butler (2005), one cannot find satisfaction without interrogating and critically reflecting the available norms given by the social and institutional context. In other words, it is only through a critical perspective on norms and guidelines that the subject can recognize itself. During the interviews, Deidra, as well as Jeff and Patrick uncritically offered socially and culturally constructed claims against the prevalent ideology of consumption in Western society. These claims promoted by external sources such as public policy discourses as well as the media foundation (Jeff), Greenpeace, the circle of simple living (Deidra), or literature on sustainable development (Patrick) were interpreted by the informants as a call for resisting consumption in general. This one-dimensional vision of sustainable consumption is clear when Helen explains: "there's a lot of people that live sustainable in the woods or whatever, 
but it takes a full life commitment. Your whole life has to be about being sustainable in order to truly do it."

A third element in living sustainable consumption as a burden was the common experience of social exclusion and solitude. The lack of critical reflection on an impersonal and indifferent regime of truth formed barriers to any possible encounter with others. The absence of identification with any local social context led Deidra and other informants to discuss sustainable consumption as alienating, creating feelings of solitude and social exclusion. For example, Marius explains that living a sustainable lifestyle by resisting owning a car and not using a heater in the winter makes him feel "alienated to some extent. Most people think I'm crazy I guess." Feelings of social exclusion are explicit in Jeff's story. Jeff is a 26 years old man who recently moved from the city to the country to live a sustainable lifestyle. In the excerpt below, Jeff explains struggling with solitude and social exclusion.

I think that in some ways always thinking about that hasn't helped the solitude issue out any at all either. Because it's really, you have all these issues and you're trying to remain calm and go out with your friends, and all of a sudden you'll be at the bar and all of a sudden you'll be in this huge, giant argument with someone about it. You know. And then that person's going to be like, this person's kind of unappealing because this person's a radical. And that's a hard thing about going back into town and maybe hanging out with people you don't know well. Because it's like all of a sudden, I get all this information from credible sources, but somehow even when I'm talking to a moderate or a moderately liberal person, somehow I end up being branded a radical. Just because I'm not-I feel like I'm being branded that way because I live out in the woods and that I'm not tugging the MSNBC party line or the Fox News party 
line. And that's really frustrating too. Because it's just like then sometimes I've left Fayetteville feeling really shitting because I'm like, why would anybody even believe me? I feel like Chicken Little or something. I don't know. (Jeff)

Jeff's one dimensional reading of sustainable consumption and his radical resistance against the ideology of consumption is not intelligible by others and thus unrecognizable. Within the literature on personhood, the impossibility to be recognized by others is discussed as a failure to achieve full personhood. For example, Fortes (1973) notes that children and slaves cannot achieve full personhood because they are not recognized as complete persons by others. Informants who express sustainable consumption as a daily burden all discussed the impossibility for being recognized and understood by others. Travis explains: "well I'm not one for this world. I'm really not one for this world. My mind is probably too aware." In reading the environmental discourse of sustainable consumption as a radical critique against consumption in general, Travis, Jeff as well as Deidra are caught up in a sphere of radical norms within which they are excluded from social encounters. In framing and living sustainable consumption outside of social encounters, these informants experience sustainable consumption as a burden to their day-to-day live.

This first theme shows how the environmental discourse on sustainable consumption and its framing of individual responsibility can be read as a one-dimension critique against consumption practices in general. Such internalization leads to experiencing sustainable consumption as a day-to-day burden. Another prominent theme which emerged from the analysis was the easiness through which some informants embraced sustainable consumption as a lifestyle and identity marker.

\section{The Natural Occurrence of Sustainable Consumption Practices}


For some informants, considering the link between consumption and environmental degradation and making the deliberate choice to consume sustainably represents the assertion of their personhood. The critical difference between the informants who experienced sustainable consumption as a burden, versus the ones who expressed the practice as an identity marker, is that the second expressed, on the one hand, an absence of absolute good or absolute norms and on the other, the integration of the practice within a complex set of relationships.

First, integrating sustainable consumption as part of one's identity demanded informants to accept that a divergence between abstract principles and practical action is constitutive of daily life. As mentioned above, all of the consumers in this study offered a clear understanding of consumption and its damaging impact on the environment and claimed that consumption has a strong and irreversible negative effect on the ecology of the planet. Yet, this perception did not always cause a categorical resistance against consumption. Rather, some informants continued experiencing pleasurable and delightful consumption practices. For example, Renee below explains her joy when finding and purchasing new dishes.

Renee: Well, actually I've been looking for new dishes for about 2 years, just waiting until I found just the right ones. So I knew I needed, I knew that I wanted to replace our dishes, because they don't really -the dishes I have don't really feel good to me.

Interviewer: What do you mean, "feel good"?

Renee: $\quad$ They just don't fit or reflect what, the way I am right now or the way the cabin is right now. It sounds kind of weird, doesn't it? But I think as an artist particularly, you have those connections. If you pick up a glass or something, it isn't just something you don't care about. It has some meaning to it. When I just found them, we were, we had gone to my sister's wedding in 
California, and we were just killing time, looking around shops and stuff, and I just saw them and I said, "There they are! I know those are the dishes I want." And Ken liked them too. So that's one thing that's different about our house. Usually one or the other person just sort of designs, decorates, and the other person relinquishes, is what I've observed. And it's usually, the woman decorates and the man fishes or something. We have, both of us are very opinionated about what goes on in here, even down to selecting dishes and because the cabin is so small, everything has to have meanings to both of us. It has to be special. So I can't go out and buy dishes and bring them home. We have to both approve them. And it matches our personality. It is such a reflection of who we are and what we were. And, you know, we don't have any extra stuff. There's no - it's easy to clean. It's just, it's a fun place to live.

Renee is a 58 year old married woman who lives a minimalist sustainable lifestyle in a rural area. Renee reflects on the environmental impact of her consumption and adopts sustainable practices such as being a vegetarian, growing her own vegetables, resisting purchasing any chemicals, or limits her travels and energy usage. Although Renee is a selfproclaimed sustainable consumer, she does not denigrate consumption and consciously refrains from defining what absolute good is or what the absolute norms of sustainable consumption are. In enhancing the value of the object of consumption, Renee emphasizes that consuming is not anti-thesis to sustainability but an essential means by which she expresses her identity, care for nature, and linkages to others. Connolly and Prothero (2003) support that consumption does not oppose sustainability and call public policy makers to acknowledge the sociology of consumption. In their study on the consumption habits of Irish consumers, they emphasize that consumption allows consumers to express a 'material green' 
identity, which focuses on recycling and waste problem rather than consumption issue as detrimental to the natural environment. Accepting consumption activities as joyful and meaningful practices whilst, at the same time, understanding the relationship between consumption and the environment allows to internalize sustainable consumption as a practice situated within a larger practice of acts that one performs to maintain and establish relationships toward oneself, toward others, and toward nature. Accordingly, internalizing sustainable consumption implies an understanding of the relationship between consumption and the environment as well as a reflexive critique of this relationship.

Second, informants who internalized sustainable consumption as part of their life and identity situated the practice within the context of an address to another, vacating the selfsufficient, autonomous individual to address the self elsewhere, in relations to others. The importance of addressing others in practices of sustainable consumption is explicit in Alicia's story as she situates the practice not within the purity of abstract principles, but within her relationships with an already-constituted social world.

A lot of people feel very guilty about buying things and what they have and how much they have and how much they buy and how much they consume and they are really able to articulate and draw a line for you of where are the products that they have bought have come from and every single step along the way about what's happened to it and how much oil's been used in making it and various other things. Um, and I think that that's really important -to know what you're buying and to know how much energy has been used to make it and therefore, what the cost is beyond the cost that you have, have had to your own wallet. You know, what the bigger cost is, um, to the planet. But at the same time, I guess there's a part of me that is, because of my own personal experience, so grateful to be living that I feel that there's also a part where we have to love life. And enjoy 
what our, um, what humanity has created and enjoy different parts of that, and make sure that we, we truly are living in a way that nourishes us. And sometimes, having some small things that may be goods of consumption that nourish our being in some kind of way, it must also be okay. (Alicia)

As an environmentalist student, Alicia understands the link between consumption and environmental degradation. Yet, her awareness does not translate as burden. Instead of feeling guilty of consuming, Alicia discusses consumption practices and personal possessions as constitutive of her identity and thus cannot be eliminated in the name of sustainability. Importantly, when describing her sustainable consumption, Alicia does not define a selfcontained, autonomous individual who makes sustainable choices based on an absolute truth. On the contrary, Alicia internalizes sustainable consumption as a fluid concept connecting her with others on a moral, ecological and social significance. She refers to her sustainable practices and her identity as living with "a sense of connectedness with other people and unity with other people and I look at nature, and I feel a sense of connectedness and unity with all that is living. And all that has life in it. Um, and my identity is formed on that connectedness." Clear to Alicia's story is that the link between consumption and environmental degradation is internalized in the context of others and in interconnectivity with the social and natural system. Similarly, Laura ties sustainable consumption to others and explains: "I try to buy things that make a difference in someone else's life and sometimes have to pay more." Incorporating others in practices of sustainable consumption shows the mutual constituency of people, consumption and nature in the shaping of the practice. This mutual constituency in the shaping of sustainable consumption is further exemplified by Fred below. 
Fred: $\quad$ I have fun taking them down to the recycling center and you get to meet all the fellow recyclers and you all talk and you chunk cans and bottles. And it's fun.

Interviewer: So you meet new people?

Fred: $\quad$ Yeah, you meet new people and you meet different people, people who are like-minded. Because people who recycle seem to have, I don't know, they have a certain personality. It's like we all have a common thread, that we all have a common connection. It's like dog people who take their pets out to the park and play, they all automatically have a common thread of the dog. We all have that common thread of recycling and the betterment of our community and we're volunteering for this. So you automatically assume people are better than what they are. You give them benefit of the doubt before you actually know them. Oh, they have to be good people. They spend their free time recycling when they could just throw it in the garbage and not care. They actually care about the community. They've got to be good people.

For Fred, being part of a recycling group and participating in sustainable consumption are symbolic practices that serve binding-in functions to a totality beyond the self, in ties with others, consumption and nature. As Fred explains, recycling serves as a "common threat" linking "good people" together. Clearly, Fred experiences recycling as a social occasion to develop relationships with others and depicts sustainable consumption, not as a selfregulating mechanism, but as a system maintained in full interconnectedness and communication with others. In this view, participants in sustainable consumption are not necessarily responsible and in control individuals responding to sustainability guidelines, but are persons who construct their social world and simultaneously their identity in connection 
to others. By embracing collectivity, informants internalize a local social shaping of sustainable consumption whose communication and interaction can catch them in negotiation with culturally and socially defined roles.

\section{Discussion}

Literature on sustainable consumption frequently discusses the concepts of green consumer (Elkington et al. 1990, Moisander 2007, Moisander and Pesonen 2002), political consumerism (Micheletti 2003, Micheletti et al. 2009, Lewis and Potter 2011), ethical voter (Shaw et al. 2006, Connolly and Prothero 2003, Prothero and Fitchett 2000), "material-green consumers" (Connolly and Prothero 2003), and ethical consumerism (Dolan 2002) to describe consumers who voluntarily engage in the consumption practices that are defined as ecologically and environmentally friendly (Connolly and Prothero 2003, Connolly and Prothero 2008). These discussions, combined with the political and environmental discourses that attempt to address environmental problems through individuals' personal consumption, mainly frame sustainable consumption as a positively valued practice and posit the sustainable consumer as a 'good citizen' (Soper 2004) who does not "jeopardize the needs of future generations" (Ministry of Environment Norway 1994) and adopt sustainable practices "in the interest of our future welfare and that of our descendants" (United Nations Millennium Declaration 2000).

In view of the notion of personhood, framing sustainable consumption as a positively valued practice performed by individuals who "will opt wherever possible for fair trade and more environmentally friendly goods or services, to spend time cooking rather than use fast food, to walk or cycle rather than to drive" (Soper, 2004, p. 113) can generate, over time, objectified aspects of personhood (that of sustainable consumer and of sustainable consumption practices) that are subjectively learned and performed in social interactions. 
Indeed, whilst all of the consumers who participated in this study claimed that consuming within ecological limits and in an environmentally-friendly manner was a positive and beneficial practice against issues of ecological declines, waste production, and/or exhaustion of natural resources, they learned, interpreted, and experienced the practice differently. Some of the informants practiced sustainable consumption effortlessly and others discussed integrating the practice into their lifestyle as a constant hardship. Thus, although association with sustainable practices may empower consumers to send market signals (Shaw et al. 2006, Connolly and Prothero 2003, Prothero and Fitchett 2000), to express "material-green" identification (Connolly and Prothero 2003), to construct 'ethical selving' (Varul 2009), or to experience alternative hedonism (Soper 2004), it can be lived as a daily burden.

Considering the concept of personhood in sustainable consumption research emphasizes that the practices by means of which actors construct their social world, and simultaneously their identity, are not isolable acts but are systematically linked to others. As such, sustainable consumption is an integral part of the same social and cultural system that enables people to relate to one another. When sustainable consumption is understood as an individual task and a resistance against consumption in general, the practice is experienced with struggles and hardship. The hardship of consuming sustainably is linked to a culturally objectified condemnation against our current consumption driven society, which ultimately tends to not only cut the individual off from mainstream consumer culture but also disregards the basis for meaningful engagement within this world (Black and Cherrier, 2010; Connolly and Prothero, 2003). As Cherrier et al. (2012) have argued our current consumer culture, where shopping, interacting with things and consuming are important to social interactions, makes it difficult to condemn consumption without alienating the person. Many people may therefore practice sustainable consumption because they have accepted the necessity of political consumerism (Micheletti 2003, Micheletti et al. 2009), but experience the practice as 
socially alienating, thus causing hardship to daily life. In addition, the wide variety of trademarks, labels and packaging from the product side combined with prescriptions from the government, fair trade businesses, or organic co-operations and the constraints from the consumer's side, can make sustainable choices highly erratic and troublesome. These considerations imply that promoting self-contained and unitary visions of sustainable consumption may contradict with other things, persons, and ideas that inhabit the social space of consumers.

Importantly, the difficulties to integrate sustainable consumption into one's lifestyle and one's identity is not an indication of the failure to allocate environmental responsibility on the consumer but rather highlights that promoting particular categories of sustainable consumers and criteria for their sustainable identity may contradict with a range of activities that are regarded as centrally and normatively important to our current consumer culture and thus make the image and ideals of sustainable consumption unpractical in daily life. Nonetheless, while sustainable consumption may be experienced as a daily burden, integrating the practice into one's lifestyle and identity can also occur naturally. As the study shows, some sustainable consumers discussed sustainable consumption in terms of a flexible practice, well integrated in their social context. Such understanding was linked to an absence of absolute resistance against consumption in general and to the social integration of the practice. The fluidity of sustainable consumption and its integration with non-sustainable consumption activities captures people's multiplicity and their interconnectiveness and thereby potentially offers the utopian role they want to play in society and encourages the problem solving that is necessary to achieve the sustainable dream we share. 
Figure 1: Sustainable consumption experiences
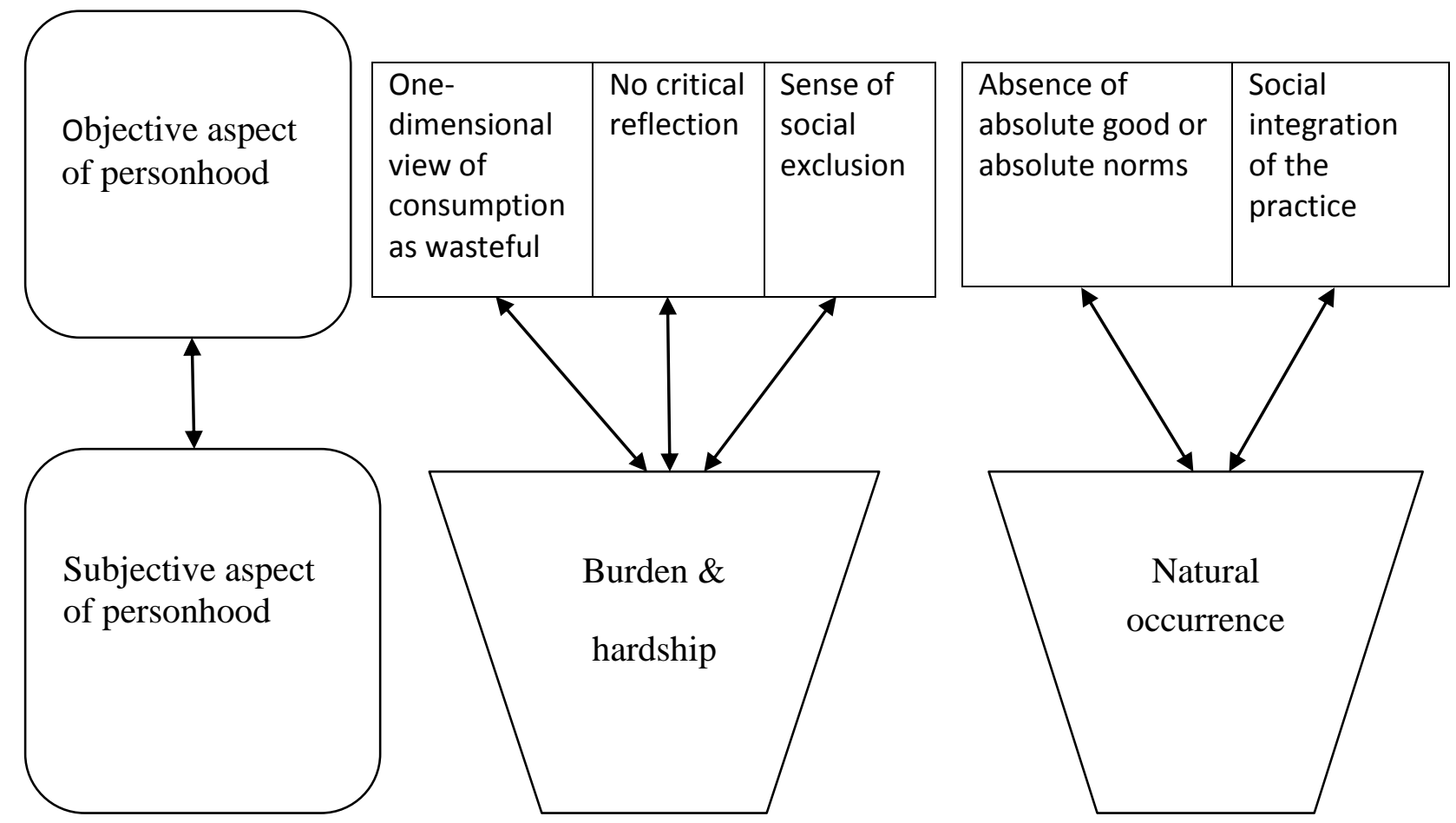


\section{REFERENCES}

Autio, M., Heiskanen, E. \& Heinonen, V. (2009). 'Narratives of 'green' consumers - the antihero, the environmental hero and the anarchist.' Journal of COnsumer Behavior, $8: 1,40-53$.

Bailie, G. (2006). 'The imitative self: the contribution of René Girard.' In P. C. Vitz \& S. M. Felch (Eds.) The Self: Beyond the postmodern crisis: 3-24. Wilmington, DE: ISI books.

Bell, D. (2004). 'Creating Green Citizens? Political Liberalism and Environmental Education.' Journal of Philosophy of Education, 38:1, 37-54.

Berkin, C., Carrigan, M. \& Szmigin, I. (2006). 'Empowerment, Waste and New Consumption Communities.' international journal of sociology and social policy, 26:1/2, 32-47.

Black, I. \& Cherrier, H. (2010). 'Anti-consumption as part of living a sustainable lifestyle: daily practices, contextual motivations and subjective values.' Journal of COnsumer Behavior, 9:6, 437-53.

Chatzidakis, A., Hibbert, S., Mittusis, D. \& Smith, A. (2004). 'Virtue in Consumption?' Journal of Marketing Management, 20, 527-44.

Cherrier, H. \& Murray, J. B. (2007). 'Reflexive Dispossession and the Self: Constructing a Processual Theory of Identity.' Consumption, Markets \& Culture, 10:1, 1-30.

Cherrier, H., Szuba, M. \& Ozcaglar-Toulouse, N. (2012). 'Barriers to Downward Carbon Emission: Exploring Sustainable Consumption in Face of the Glass Floor.' Journal of Marketing Management, 28:3/4, 397-419.

Cohen, M. J. \& Murphy, J. (2001). Exploring sustainable consumption: environmental policy and the social science. Amsterdam: Elsevier.

Collins, A. J. (2004). 'Can we learn to live differently? Lessons from Going for Green: a case study of Merthyr Tydfil (South Wales).' International Journal of Consumer Studies, 28:2, 202-11.

Connolly, J. \& Prothero, A. (2003). 'Sustainable consumption, consumption, consumers and the commodity discourse.' Consumption, Markets \& Culture, 6:4, 275-91.

Connolly, J. \& Prothero, A. (2008). 'Green Consumption: Life-politics, risk and contradictions.' Journal of Consumer Culture, 8:1, 117-45.

Denzin, N. K. \& Lincoln, Y. S. (1998). Collecting and interpreting qualitative materials. Thousand Oaks, Calif.: Sage Publications.

Dolan, P. (2002). 'The Sustainability of "Sustainable Consumption".' Journal of Macromarketing, 22:2, 170-81.

Du Gay, P. (2004). 'Self-Service: Retail, Shopping and Personhood.' Consumption Markets \& Culture, 7:2, 149-63.

Du Gay, P. (2007). Organizing Identity. London, UK: Sage publication.

Du Gay, P., Salaman, J. G. \& Rees, B. (1996). 'The conduct of management and the management of the conduct: Contemporary managerial identity.' Journal of Management Studies, 33:3, 263-82.

Elkington, J., Hailes, J. \& Makower, J. (1990). The green consumer. New York: Penguin Books.

Fortes, M. (1973). 'On the concept of person among Tallensi.' In G. Dieterlen (Ed.) La notion de personne en Afrique Noire: 283-319. Paris: Editions du centre nationale de la recherche scientifique.

Gaylin, W. \& Jennings, B. (2003). The perversion of autonomy: Coercion and constraints in a liberal society. Washington D.C.: Georgetown University Press. 
Goodenough, W. H. (1965). 'Rethinking status and role: toward a general model of the cultural organization of social relationships.' In M. Banton (Ed.) The relevance of models for social anthropology: 1-24. London: Routledge.

Heiskanen, E. \& Pantzar, M. (1997). 'Toward Sustainable Consumption: Two New Perspectives.' Journal of Consumer Policy, 20:4, 409-42.

Hinchlifffe, S. (1996). 'Helping the Earth Begins at Home: The social construction of socioenvironmental responsibilities.' Global Environmental Change, 6:1, 53-62.

Husserl, E. (2000). L'idee de la phenomenologie. Paris, France: Presses Universitaires de France.

Jackson, M. \& Karp, I. (1990). Personhood and Agency. Washington DC, US: Smithsonian Institution Press.

Jenkins, R. (1996). Social identity. London: Routledge.

La Fontaine, J. S. (1985). 'Person and individual: some anthropological reflections.' In M. Carrithers, S. Collins \& S. Lukes (Eds.) he category of the person: anthropology,philosophy, history. Cambridge: Cambridge University Press.

Lewis, T. \& Potter, E. (2011). Ethical Consumption: A Critical Introduction. London, UK: Routledge.

Mauss, M. (1939). 'Une categorie de l'esprit humain: La notion de personne, celle de moi.' Journal of the Royal Anthropological Institute, 68, 263-82.

Mauss, M. (1950). 'Essai sur le don.' Sociologie et Anthropologie, 143-279.

Mauss, M. (1985). 'a category of the human mind: the notion of person, the notion of self.' In M. Carrithers, S. Collins \& S. Lukes (Eds.) the category of the person: anthropology, philosophy, history. Cambridge: Cambridge University Press.

Merleau Ponty, M. (1942). La structure du comportement. Paris, France: Presses Universitaires de France.

Micheletti, M. (2003). Political Virtue and Shopping: Individuals, Consumerism, and Collective Action. New Yrok, NY: Palgrave MacMillan.

Micheletti, M., Follesdal, A. \& Stolle, D. (2009). Politics, Products, And Markets: Exploring Political Consumerism Past And Present New Brunswick, New Jersey: Transaction Publishers.

Ministry of Environment Norway, N. (1994). 'Report of the Sustainable Consumption Symposium.' In M. o. t. E. Norway (Ed.). Oslo: Ministry of the Environment Norway.

Moisander, J. (2007). 'Motivational Complexity of green consumerism.' International Journal of Consumer Studies, 31, 404-09.

Moisander, J. \& Pesonen, S. (2002). 'Narratives of Sustainable ways of living: Consructing the Self and the Other as a Green Consumer.' Management Decision, 40:4, 329-42.

Prothero, A., Dobscha, S., Freund, J., Kilbourne, W. E., Luchs, M. G., Ozanne, L. K. \& Thogersen, J. (2011). 'sustainable consumption: opportunities for consumer research and public policy.' Journal of Public Policy \& Marketing, 30:1, 31-38.

Prothero, A. \& Fitchett, J. A. (2000). 'Greening Capitalism: Opportunities for a Green commodity.' Journal of Macromarketing, 20:1, 46-55.

Rorty, A. O. (1976). The identities of persons. Berkeley, US: University of California Press.

Rorty, R. (1989). Contingency, irony, and solidarity. Cambridge, UK: Cambridge University Press.

Sachs, W. (1999). 'sustainable development and the crisis of nature: on the political anatomy of an oxymoron.' In F. Fischer \& M. A. Hajer (Eds.) Living with Nature: 23-42. Oxford: Oxford University Press.

Seyfang, G. (2006). 'Ecological Citizenship and sustainable consumption: Examining local Organic Food Networks.' Journal of Rural Studies, 22:1, 383-95. 
Shankar, A., Cherrier, H. \& Canniford, R. (2006). 'Consumer Empowerment: A Foucauldian Interpretation.' European Journal of Marketing.

Shaw, D., Newholm, T. \& Dickinson, R. (2006). 'Consumption as Voting: An Exploration of Consumer Empowerment.' European Journal of Marketing, 40:9/10, 1049-67.

Shove, E. (2005). 'Changing human behaviour and lifestyle: a challenge for sustainable consumption?' In I. Ropke \& L. Reisch (Eds.) Consumption - Perspectives from ecological economics: 111-32. Cheltenham: Elgar.

Soper, K. (2004). 'Rethinking the "Good Life": The Consumer as Citizen.' Capitalism Nature Socialism, 15:3, 111-16.

Strutton, D., Vitell, S. J. \& Pelton, L. E. (1994). 'How Consumers May Justify Inappropriate Behavior in Market Settings: An Application on the Techniques of Neutralization.' Journal of Business Research, 30:3, 253-60.

Thogersen, J. (2005). 'How may consumer policy empower consumers for sustainable lifestyles?' Journal of Consumer Policy, 28, 143-78.

Thompson, C. J. (1997). 'Interpreting consumers: A hermeneutical framework for deriving marketing insights from the texts of consumers' consumption stories.' Journal of Marketing research, 34:4, 438-56.

Thompson, C. J., Locander, W. B. \& Pollio, H. R. (1989). 'Putting Consumer Experience back into Consumer Research: The Philosophy and Method of ExistentialPhenomenology.' Journal of Consumer research, 16:4, 133-47.

United Nations Millennium Declaration, U. (2000). 'General Assembly resolution 55/2 of 8 September 2000.' In OHCHR (Ed.). Geneva: Office of the United nation High Commissioner for Human Right Report.

Varul, M. Z. (2009). 'Ethical selving in cultural contexts: fairtrade consumption as an everyday ethical practice in the UK and Germany.' International Journal of Consumer Studies, 33:1, 183-89. 